\title{
ESTIMATION OF WHEELS' NORMAL REACTION FORCES OF AUTOMOBILE IN STEADY-STATE CURVILINEAR MOTION
}

\author{
Piotr Fundowicz*, Hubert Sar, Mateusz Brukalski
}

Institute of Vehicles and Construction Machinery Engineering, Warsaw University of Technology, Warsaw, Poland

*E-mail of corresponding author: piotr.fundowicz@pw.edu.pl

\section{Resume}

Computer simulation seems to be one of the cheapest and relatively fast methods of investigating vehicle motion. Thereby, it may be important in the case of calculations for the reconstruction of traffic incidents. In particular, that may be important to answer the following question: How wheels' normal reaction forces differ during the cornering of a vehicle?

In this article, the authors presented how the normal reaction forces vary in the case of roll motion of a vehicle body. Suitable mathematical equations are presented. Furthermore, the measurements of the height of the centre of gravity were performed, which was necessary to obtain the normal reaction forces while vehicle body rolls. The authors decided to apply dimensionless coefficients, which represented the properties of a front and rear suspension. Additionally, dimensionless parameters were applied to consider the impact of asymmetrical distribution of vehicle load on normal reaction forces of wheels on a road surface.

Available online: https://doi.org/10.26552/com.C.2021.4.B317-B324

\section{Article info}

Received 17 September 2020

Accepted 3 February 2021

Online 27 August 2021

\section{Keywords:}

vehicles, safety, traffic accidents reconstruction, normal reaction forces, vehicle motion modelling, road tests, curvilinear motion

ISSN 1335-4205 (print version) ISSN 2585-7878 (online version)

\section{Introduction}

Automotive safety depends on many factors related to a vehicle, driver and space surrounding them. If one discusses problems connected with vehicles, one can apply different mathematical apparatus to describe vehicle's motion, for example the Lozia's model [1]. Considering surrounding, one usually has different weather conditions or different road surfaces being in contact with tyres [2]. Considering a driver, one can see the analysis of a driver's behaviour [3]

Knowledge of estimation of the changeability of wheels' normal reaction forces on the road surface cannot be skipped in some circumstances. It takes place, if one wants to simulate vehicle's curvilinear motion more precisely. Very often it cannot be skipped even for the steady-state conditions. To be able to observe this issue, one must know some basic parameters of a vehicle, for example mass of a vehicle, location of the centre of mass, including the height of the centre of gravity above road surface. One of traffic incidents, for which the changeability of normal reaction forces is necessary, is rollover of automobile.

As for the use of vertical response modelling, this can be found for example in [4] and [5]. The double-track vehicle model is used there, including the roll motion of a vehicle's body, thus influencing normal reaction forces. Those forces also depend on suspension properties such as stiffness and damping. Next paper [6] shows similar approach, but with considering the risk analysis of a rollover road incident. The rollover accident is more probable for automobiles with high centre of mass. It was very interestingly discussed in work [7], where the special pressure was put on steering and braking system to prevent the rollover. Application of the normal forces prediction for the planar model of a vehicle was discussed in [8]. The normal forces have the influence both on longitudinal and lateral forces between the tyre and a road, according to proposed tyres characteristics. Of course, it is possible to measure the normal reaction forces during the road tests. To perform it, special force sensors mounted on a special tyre rim are applied as presented in paper [9].

\section{Methodology applied in the research}

\subsection{Position of the centre of mass relative to the vehicle's axis and relative to the longitudinal plane}

In general case, position of the vehicle's centre of mass describes its distance from the front and rear axles, distance from longitudinal median plane $(x 0 z)$ and height above the ground - Figure 1. Symbol S.M. means the centre of mass.

The dimensionless values $L_{1}, L_{2}$ and $H$, describing the mass distribution in the vehicle were introduced for the analyses. It allowed for comparison of suspension's properties of vehicles with different dimensions: 

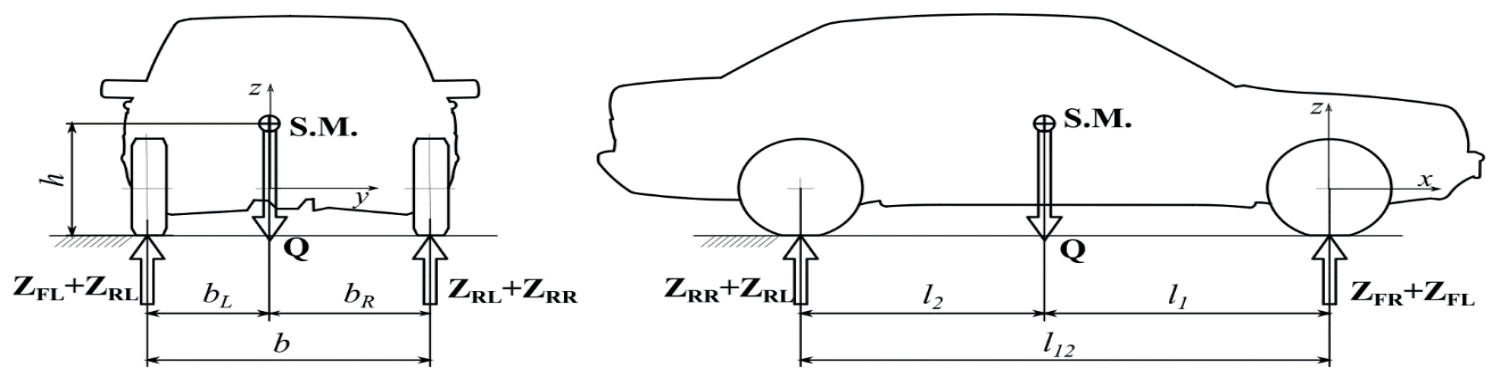

$\mathbf{Q}, \mathbf{Z}_{\mathrm{FR}}, \mathbf{Z}_{\mathbf{F L}}, \mathbf{Z}_{\mathrm{RR}}, \mathbf{Z}_{\mathrm{RL}}-$ vertical forces (described in text)

S.M. - the centre of mass

Figure 1 Location of the centre of mass $Z_{F R}, Z_{F L}[N]$ - front axle vertical reaction forces, respectively under right, left wheel, $Z_{R R}, Z_{R L}[N]$ - rear axle vertical reaction forces, respectively under right, left wheel, $Q$ [N] - weight of a vehicle, S.M. - centre of mass of a vehicle, $b_{L}[\mathrm{~m}]$ - distance between the left wheel and centre of mass in the $y$ axis direction, $b_{R}[\mathrm{~m}]$ - distance between the right wheel and centre of mass in the $y$ axis direction, $l_{12}[\mathrm{~m}]$ - wheelbase, $l_{1}, l_{2}[\mathrm{~m}]$ - distances of the centre of mass respectively from the front and rear axle of a vehicle, measured in the direction of $x$ axis, $h[m]$ - height, at which the centre of mass is located (in relation to ground), $b[\mathrm{~m}]$ - wheels track, wheels track $b$ was assumed as equal for the front and rear axle

- $\quad L_{1}, L_{2}$ [-] - position of the vehicle's centre of mass relative to the axle normalized to the wheelbase:

$L_{1}=\frac{l_{1}}{l_{12}}, L_{2}=\frac{l_{2}}{l_{12}}$,

where:

$l_{1}, l_{2}$ - distances of the centre of mass from the front and rear axle of the vehicle, measured in longitudinal direction, $l_{12}$ - wheelbase,

- $H$ [-] - location of the vehicle's centre of mass above the ground, normalized to the wheelbase:

$H=\frac{h}{l_{12}}$,

where:

$h$ - height, at which the centre of mass is located.

The condition of the vehicle is described by the acceleration values in the longitudinal $\left(a_{r}\right)$ and lateral $\left(a_{y}\right)$ directions. Later in the text, they are replaced by dimensionless coefficients:

- -braking intensity:

$\gamma_{x}=\frac{a_{x}}{g}$

where:

$g\left[\frac{m}{s^{2}}\right]$ - gravitational acceleration,

- $\quad$ steer intensity:

$\gamma_{y}=\frac{a_{y}}{g}$

Static equations are presented below:

$$
\begin{aligned}
& Z_{F R}+Z_{F L}+Z_{R R}+Z_{R L}=m \cdot g, \\
& Z_{F R}+Z_{F L}=m \cdot g \cdot\left(L_{2}+H \cdot \gamma_{x}\right), \\
& Z_{F R}+Z_{R R}=m \cdot g \cdot\left(B_{L}+\frac{H}{B} \cdot \gamma_{y}\right),
\end{aligned}
$$

where:

indices: $F, R$ - front and rear axle, $R, L$ - right and left wheels, respectively,

$\mathrm{m}[\mathrm{kg}]$ - mass of a vehicle,

$Z[\mathrm{~N}]$ - vertical forces between the wheels and pavement, $B[-]$-wheels track normalized to the wheelbase:

$B=\frac{b}{l_{12}}$.

$B_{L}, B_{R}$ (optionally) - position of the vehicle's centre of mass relative to the axle normalized to the wheels' track:

$B_{L}=\frac{b_{L}}{b}, B_{R}=\frac{b_{R}}{b}$.

If a vehicle moves on a plane, then the relationship between deflections ( $\zeta$ ) of a suspension of individual wheels (assuming the same wheels track $b$ ) of the front and rear axle) is satisfied:

$\zeta_{F R}-\zeta_{F L}=\zeta_{R R}-\zeta_{R L}$

where:

$\zeta_{F R}, \zeta_{F L}[\mathrm{~m}]$ - deflection of the front axle suspension of respectively right and left wheel,

$\zeta_{R R}, \zeta_{R L}[\mathrm{~m}]$ - deflection of the rear axle suspension of respectively right and left wheel.

Normal reaction forces of individual wheels on the surface are associated with suspension deflections and torsion of both front and rear anti-roll bar (if a vehicle is equipped with them):

- respectively front right, front left normal reaction force:

$$
Z_{F R, F L}=k_{F} \cdot \zeta_{F R, F L} \mp \frac{2 \cdot M_{s F}}{b},
$$

- respectively rear right, rear left normal reaction force: 
$Z_{R R, R L}=k_{R} \cdot \zeta_{R R, R L} \mp \frac{2 \cdot M_{S R}}{b}$

where:

$k_{F}\left[\frac{N}{m}\right]$ - coefficient of vertical stiffness of the left-hand or the right-hand side of front suspension,

$k_{R}\left[\frac{N}{m}\right]$ - coefficient of vertical stiffness of the left-hand or the right-hand side of rear suspension,

$M_{s F}[\mathrm{Nm}]$ - torsional torque of the front axle antiroll bar, $M_{s R}[\mathrm{Nm}]$ - torsional torque of the rear axle antiroll bar.

It can be assumed that the torques resulting from functioning of the anti-roll bars $\left(M_{s F}, M_{s R}\right)$, which increase the angular stiffness of the suspension, are proportional to the roll angle $\varphi$ of the lateral inclination of vehicle body, associated with asymmetrical deflection of the suspension:

$$
\begin{aligned}
& M_{s F}=k_{s F} \cdot \varphi=k_{s F} \cdot \frac{\zeta_{F R}-\zeta_{F L}}{b}, \\
& M_{s R}=k_{s R} \cdot \varphi=k_{s R} \cdot \frac{\zeta_{R R}-\zeta_{R L}}{b},
\end{aligned}
$$

where:

$k_{s F}, k_{s R}$ - proportionality constants.

Considering the above relationships from Equations (11) and (12), the suspension deflections can be determined as:

$$
\begin{aligned}
& \zeta_{F R, F L}=\frac{Z_{F R, F L} \cdot k_{F}-\left(Z_{F R}+Z_{F L}\right) \cdot S_{F}}{k_{F}^{2}-2 \cdot k_{F} \cdot S_{F}}, \\
& \zeta_{R R, R L}=\frac{Z_{R R, R L} \cdot k_{F}-\left(Z_{R R}+Z_{R L}\right) \cdot S_{R}}{k_{R}^{2}-2 \cdot k_{R} \cdot S_{R}},
\end{aligned}
$$

where:

$S_{F, R}$ - supporting variables:

$S_{F, R}=\frac{2 \cdot k_{s F, s R}}{b^{2}}$.

After substituting Equations (15) and (16) into Equation (10), the following equation is obtained:

$Z_{F R} \cdot K_{R}-Z_{F L} \cdot K_{R}-Z_{R R} \cdot K_{F}+Z_{R L} \cdot K_{F}=0$,

where:

$K_{F, R}$ - supporting variables:

$$
K_{F, R}=k_{F, R}-2 \cdot S_{F, R}=k_{F, R}-\frac{4 \cdot k_{s F, s R}}{b^{2}} .
$$

Together with Equations (5)-(7), the system of equations is created:

$$
\left[\begin{array}{cccc}
1 & 1 & 1 & 1 \\
1 & 0 & 1 & 0 \\
1 & 1 & 0 & 0 \\
K_{R} & -K_{F} & -K_{R} & K_{F}
\end{array}\right] \cdot\left[\begin{array}{c}
Z_{F R} \\
Z_{R R} \\
Z_{F L} \\
Z_{R L}
\end{array}\right]=m \cdot g \cdot\left[\begin{array}{c}
1 \\
L_{2}+H \cdot \gamma_{x} \\
B_{L}+\frac{H}{B} \cdot \gamma_{y} \\
0
\end{array}\right],
$$

whose solution are the values of normal reaction forces of individual wheels on the surface.

In the static state, when the vehicle is positioned on a horizontal plane, expressions describing the wheel loads are as follows:

$Z_{F R}=m \cdot g\left(\frac{L_{2}+H \cdot \gamma_{x}+T_{F}}{2}+R_{F} \cdot \gamma_{y}\right)$

$Z_{F L}=m \cdot g\left(\frac{L_{2}+H \cdot \gamma_{x}-T_{F}}{2}-R_{F} \cdot \gamma_{y}\right)$

$Z_{R R}=m \cdot g\left(\frac{L_{1}-H \cdot \gamma_{x}+T_{R}}{2}+R_{R} \cdot \gamma_{y}\right)$,

$Z_{R L}=m \cdot g\left(\frac{L_{1}-H \cdot \gamma_{x}-T_{R}}{2}-R_{R} \cdot \gamma_{y}\right)$

where:

$R_{F, R}$ [-] - parameters describing the suspension:

$R_{F, R}=\frac{K_{F, R}}{K_{F}+K_{R}} \cdot \frac{H}{B}$,

$T_{F, R}$ [-] - parameters describing a vehicle's asymmetrical load distribution:

$T_{F, R}=\frac{2 \cdot K_{F, R}}{K_{F}+K_{R}} \cdot\left(B_{L}-0.5\right)$.

If one assumes that $\gamma_{x}=0$ and $\gamma_{y}=0$, Equations (21) - (24) are simplified to the form presented below:

$Z_{F R}=m \cdot g\left(\frac{L_{2}+T_{F}}{2}\right)$,

$Z_{F L}=m \cdot g\left(\frac{L_{2}-T_{F}}{2}\right)$

$Z_{R R}=m \cdot g\left(\frac{L_{1}+T_{R}}{2}\right)$

$Z_{R L}=m \cdot g\left(\frac{L_{1}-T_{R}}{2}\right)$

or equivalent matrix form:

$\left[\begin{array}{cccc}0 & 1 & 1 & 0 \\ 0 & 1 & -1 & 0 \\ 1 & 0 & 0 & 1 \\ 1 & 0 & 0 & -1\end{array}\right] \cdot\left[\begin{array}{c}L_{1} \\ L_{2} \\ T_{F} \\ T_{R}\end{array}\right]=\frac{2}{Q} \cdot\left[\begin{array}{c}Z_{F R} \\ Z_{F L} \\ Z_{R R} \\ Z_{R L}\end{array}\right]$.

The object of research was Hyundai Veloster (2010). In the expressions describing the wheels loads, parameters describing the suspension $\left(R_{F}, R_{R}\right)$ and parameters describing the load distribution of the vehicle $\left(L_{1}, L_{2}, H, T_{F}, T_{R}\right)$ appear. The trial measurements were carried out in the Institute of Vehicles of Warsaw University of Technology to determine these parameters for selected vehicle. The position of the centre of mass was determined by well-known method - by measuring the wheels' normal loads of a vehicle standing on a plane and then once again measuring them after lifting one of the axles - Figure 2. 
As a result of measurements for the unloaded vehicle (Hyundai Veloster (2010)), the following properties were obtained:

\subsection{Vehicle positioned horizontally}

If the normal reaction forces are estimated or measured separately for each wheel of a vehicle and if one also knows the vehicle's wheelbase $l_{12}=2.650 \mathrm{~m}$ and vehicle's width $B=1.560 \mathrm{~m}$, from the above equation the following parameters can be determined: $L_{1}, L_{2}$ describing the distance of the vehicle's centre of mass and its axle and $T_{F}, T_{R}$ - describing the distance of the centre of mass from the vehicle's symmetry plane (asymmetrical load).

For measured normal reaction forces:

$Z_{F R}=3408 \mathrm{~N}, Z_{F L}=3817 \mathrm{~N}, Z_{R R}=2570 \mathrm{~N}, Z_{R L}=2482 \mathrm{~N}$ it was calculated:

$L_{1}=0.411, L_{2}=0.588, T_{F}=-33.3 \cdot 10^{-3}, T_{R}=7.2 \cdot 10^{-3}$.
Next, the height of the centre of mass of the vehicle was obtained. It was performed in two different ways, firstly lifting the front and rear axle.

\subsection{Height of the centre of mass relative to the pavement}

The location of the centre of mass above the road surface (height of the centre of mass) was determined by the well-known method [10] through lifting one of the vehicle's axles to a known height and measuring the axle load on the surface - see Figure 2.

When the rear axle of the vehicle is raised, the front axle is weighed. The location of the centre of mass is described by the following formula (applied based on [10]):

$h=\frac{Z_{1} \cdot l_{12}-Q \cdot L_{2}}{Q \cdot \operatorname{tg} \alpha}+R$,

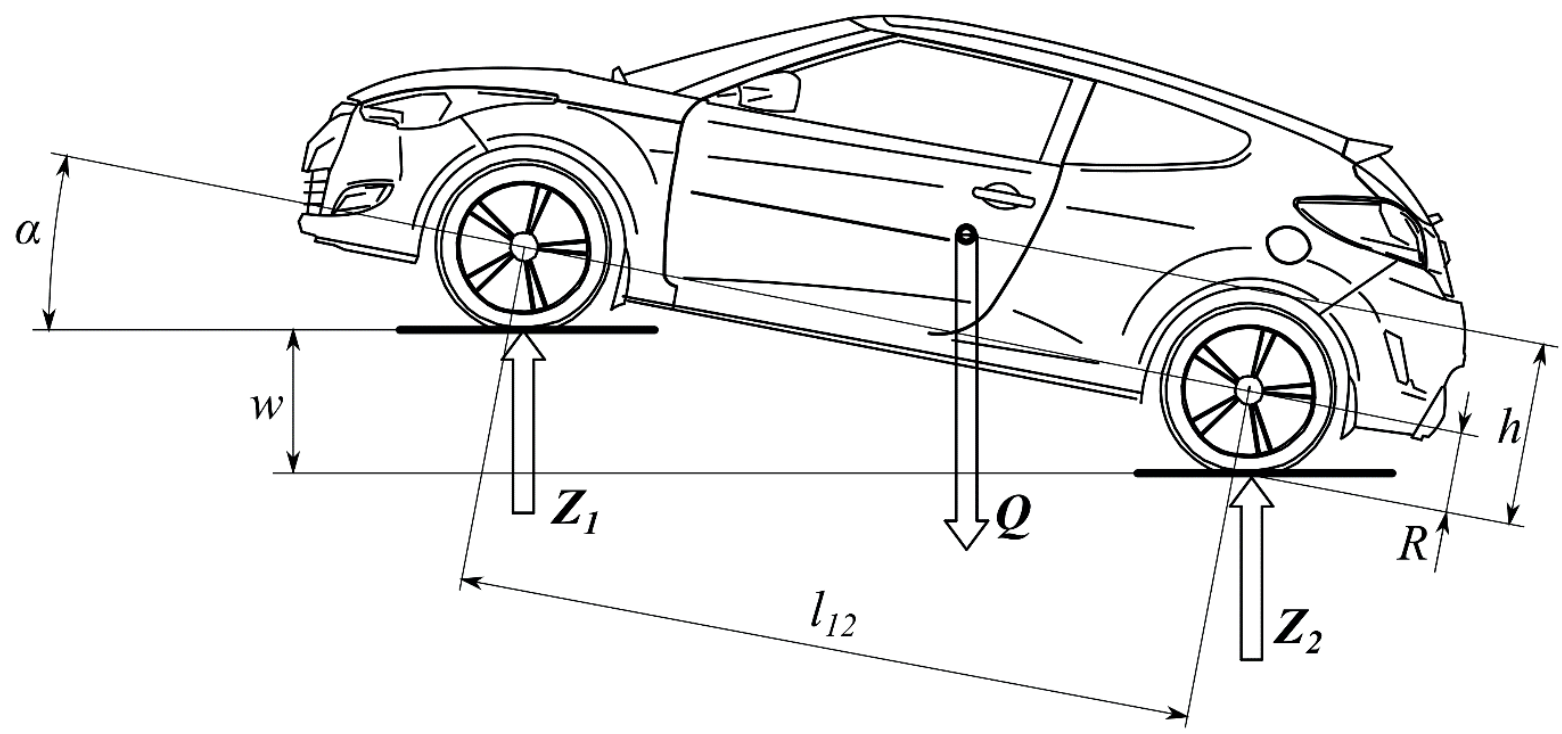

a)

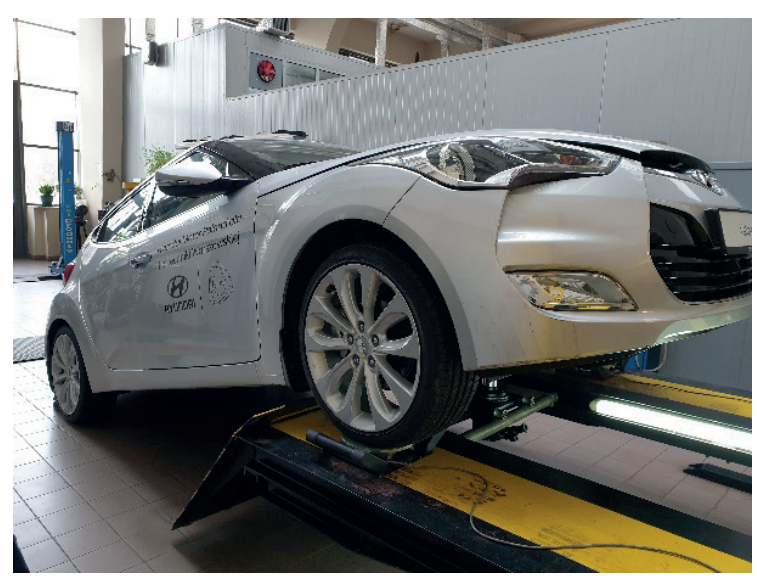

b)

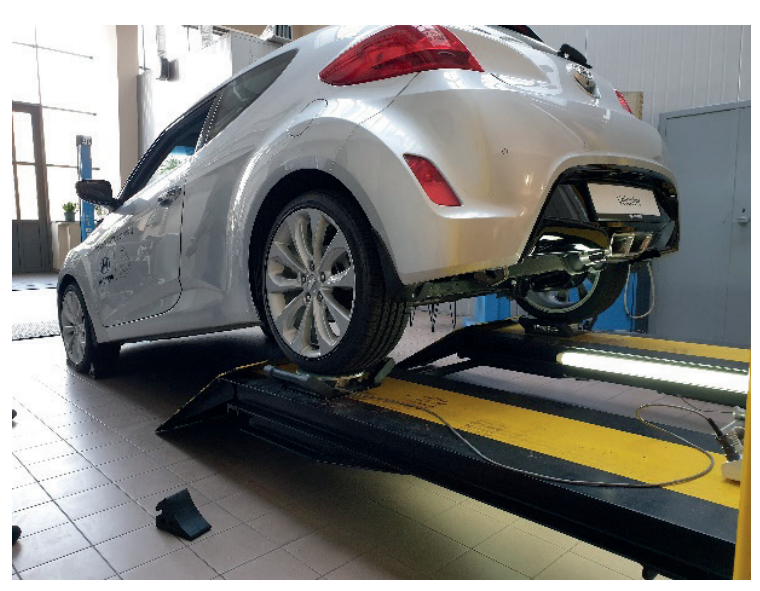

Figure 2 Method of measuring the position of the centre of mass above the pavement plane: $a$ - measurement scheme, $b$ measurement of the front axle loads when raised to a height of about $0.9 \mathrm{~m}, \mathrm{c}$ - measurement of the rear axle loads when raised to a height of about $0.6 \mathrm{~m}$ 


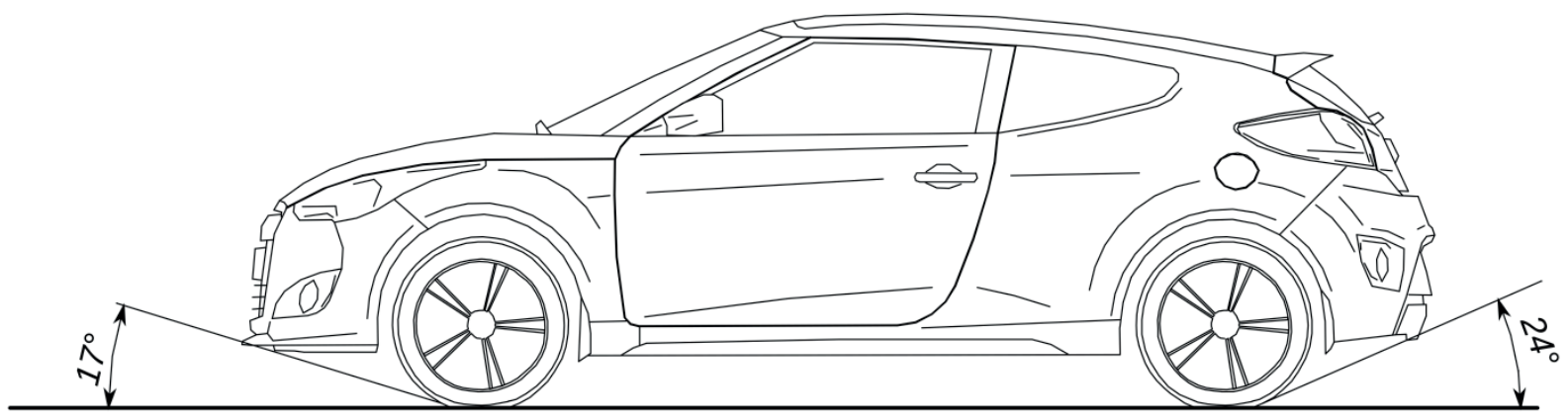

Figure 3 Approach angle and departure angle of researched vehicle

where:

$Z_{1}[\mathrm{~N}]$ - the sum of the front axle normal reaction forces on left and right wheel,

$Q[\mathrm{~N}]$ - weight of a vehicle,

$\alpha[\mathrm{rad}]$ - angle by which the vehicle was lifted:

$\sin \alpha=\frac{w}{l_{12}}$,

$l_{12}=2.650 \mathrm{~m}$ - vehicle's wheelbase,

$R=0.3 \mathrm{~m}$ - vehicle tyre's radius during tests.

When lifting the front axle of the vehicle, the rear axle is weighed and the centre of mass position is described by the formula, which is analogous to Equation (32):

$h=\frac{Z_{2} \cdot l_{12}-Q \cdot l_{1}}{Q \cdot \tan \alpha}+R$,

where:

$Z_{2}[\mathrm{~N}]$ - the sum of the rear axle normal reaction forces on left and right wheel.

Due to the relatively large front ground clearance (approach angle $\alpha=17^{\circ}$ ) in relation to the rear (departure angle $\beta=24^{\circ}$ ), the height of the rear part of the vehicle was limited by the possibility of collision of the front bumper with the road surface - see Figure 3.

The results obtained during the tests:

- lifted front axle of the vehicle:

For the height $\mathrm{w}=0.70 \mathrm{~m}$, the rear axle normal reaction force was measured:

$Z_{2}=5393 \mathrm{~N}$.

Angle between the pavement and a vehicle was: $\alpha=\arcsin \frac{w}{l_{12}}=\arcsin \frac{0.70 m}{2.650 m}=0.267 \mathrm{rad}$.

From obtained values of $Z_{2}$ and $\alpha$ height of the centre of gravity of a vehicle was calculated below.

$$
\begin{aligned}
& h=\frac{Z_{2} \cdot l_{12}-Q \cdot l_{1}}{Q \cdot \tan \alpha}+R= \\
& \frac{5393 N \cdot 2.650 m-12277 N \cdot 1.09 m}{12277 N \cdot \tan 0.267}+0.30 m=0.57 m
\end{aligned}
$$

For other values of height $w$, the following results were obtained:

$$
\begin{array}{lll}
w=0.80 \mathrm{~m}, & Z_{2}=5468 \mathrm{~N}, & h=0.58 \mathrm{~m}, \\
w=0.90 \mathrm{~m}, & Z_{2}=5507 \mathrm{~N}, & h=0.57 \mathrm{~m} .
\end{array}
$$

In analogy to the calculations accompanying the lifting of the front axle, below are presented the results of calculations of the height of the centre of gravity for the rear axle lifted.

- lifted rear axle of the vehicle:

$$
\begin{array}{lll}
w=0.47 \mathrm{~m}, & Z_{1}=7467 \mathrm{~N}, & h=0.60 \mathrm{~m}, \\
w=0.53 \mathrm{~m}, & Z_{1}=7493 \mathrm{~N}, & h=0.59 \mathrm{~m}, \\
w=0.57 \mathrm{~m}, & Z_{1}=7510 \mathrm{~N}, & h=0.59 \mathrm{~m}, \\
w=0.60 \mathrm{~m}, & Z_{1}=7513 \mathrm{~N}, & h=0.57 \mathrm{~m} .
\end{array}
$$

The result of measurements is the average of the upper presented values and equals as depicted below: $h=0.58 \mathrm{~m}$.

\subsection{Parameters describing the effect of stabilizers on wheels' loads}

The force $F_{y}$ (see Figure 4) acting on the vehicle in the transverse direction, applied at the height $H_{y}$, creates a torque that corresponds to the lateral inertial (centrifugal) force:

$F_{b}=F_{y} \cdot \frac{H_{y}}{h}$,

$h$ [m] - the height at which the vehicle's centre of mass is located.

Subsequent measurements were aimed at determining the values of parameters $R_{F}$ and $R_{R}$. For this purpose, the vehicle was loaded with lateral force applied at known height and wheels' normal reaction forces were measured - Figure 4.

This force, in turn, corresponds to the lateral acceleration of the vehicle:

$a_{y}=\frac{F_{b}}{m}=\frac{F_{b}}{Q} \cdot g$

or dimensionless indicator:

$\gamma_{y}=\frac{a_{y}}{g}=\frac{F_{y}}{Q} \cdot \frac{H_{y}}{h}$,

During the measurements, force was applied near the connection of the " $B$ " pillar with the roof of the vehicle and equalled:

$F_{y}=245 \mathrm{~N}$,

at the height of its roof:

$H_{y}=1.4 \mathrm{~m}$. 


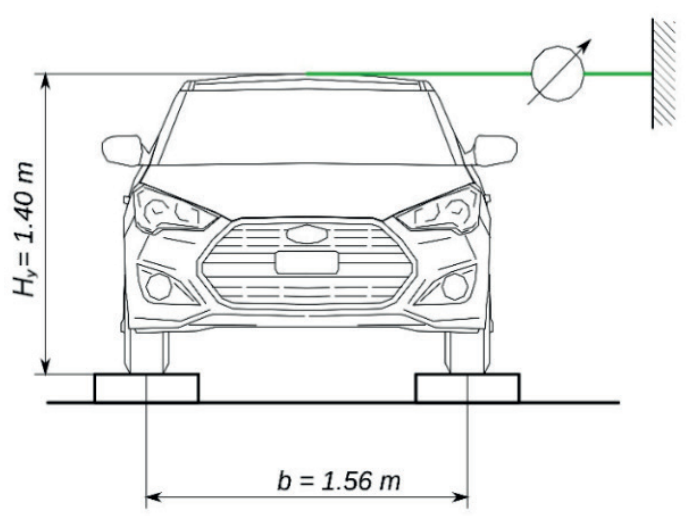

a)

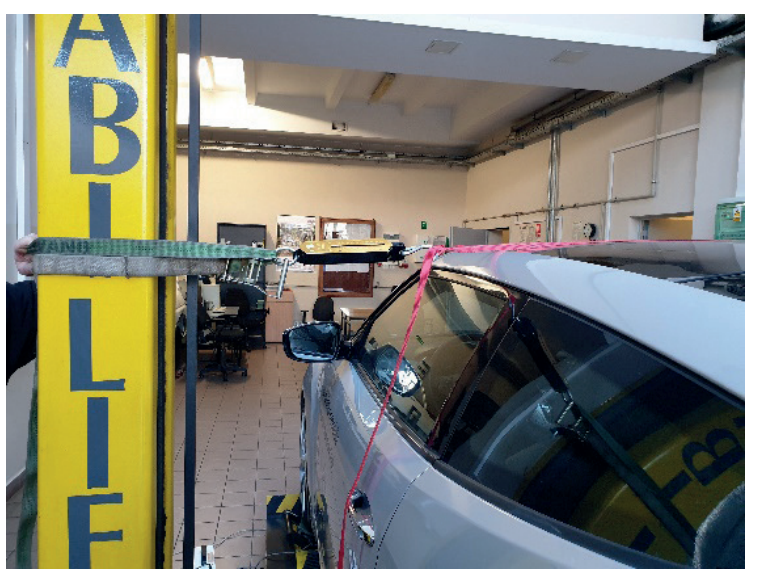

b)

Figure 4 Determination of the $R_{F}$ and $R_{R}$ parameters

It corresponds to dimensionless coefficient:

$\gamma_{y}=\frac{245 N}{12277 N} \cdot \frac{1.4 m}{0.59 m}=46.6 \cdot 10^{-3}$.

From equations describing the wheels loads on the surface, in the absence of longitudinal acceleration ( $\gamma_{x}=0$ ), the parameters $R_{F}$ and $R_{R}$, describing the effect of the stabilizers (front and rear torsion beam) on normal reaction forces, can be determined:

- calculated based on normal reaction forces of the right wheels:

$$
\begin{aligned}
& R_{F}=\frac{1}{\gamma_{y}} \cdot\left(\frac{Z_{F R}}{Q}-\frac{L_{2}+T_{F}}{2}\right), \\
& R_{R}=\frac{1}{\gamma_{y}} \cdot\left(\frac{Z_{R R}}{Q}-\frac{L_{1}+T_{R}}{2}\right),
\end{aligned}
$$

- calculated based on the load of the left wheels:

$$
\begin{aligned}
& R_{F}=\frac{-1}{\gamma_{y}} \cdot\left(\frac{Z_{F L}}{Q}-\frac{L_{2}-T_{F}}{2}\right), \\
& R_{R}=\frac{-1}{\gamma_{y}} \cdot\left(\frac{Z_{R L}}{Q}-\frac{L_{1}-T_{R}}{2}\right) .
\end{aligned}
$$

After including the data measured during the tests: $Z_{F R}=3309 \mathrm{~N}, Z_{F L}=3919 \mathrm{~N}, Z_{R R}=2472 \mathrm{~N}, Z_{R L}=2590 \mathrm{~N}$, it was given:

- based on right wheels normal reaction forces:

$R_{F}=-0.168, \quad R_{R}=-0.184$,

- based on left wheels normal reaction forces:

$R_{F}=-0.166, \quad R_{R}=-0.194$.

The difference between the results obtained from calculations based on the right and left wheels of the vehicle are due to the measurement errors, but because they are small (for $R_{F}-0.6 \%$, for $R_{R}-5.0 \%$ ), the average values were used as the test result: $R_{F}=-0.160, R_{R}=-0.189$.

The forces that were applied to the vehicle's body during the measurements were relatively small, compared to the forces that can act on the vehicle when driving along a curvilinear track. When cornering, the transverse mass forces act as a result of the inertia of the vehicle's body, while during the laboratory tests a concentrated force was applied at a selected point of the body. Applying a force, comparable to that which can occur under the normal driving conditions, could damage the vehicle body.

\subsection{Influence of the passenger's weight on the vehicle's centre of mass displacement}

Since during the reconstruction of traffic incident it makes no sense to analyse the movement of the unloaded vehicle, calculations were made to answer how loading a vehicle by a driver or a passenger influences the wheels' load. Figure 5 shows the position of the driver inside the passenger's compartment.

If the centre of mass of the unloaded vehicle with the mass $m_{P}$ is in the position described with coordinates $x_{0}, y_{0}, h_{0}$, then after loading it with the mass $m_{1}$ of the passenger with the centre of mass in $x_{1}, y_{1}, h_{1}$ points, the centre of mass of the laden vehicle will be at the point described by the coordinates:

$x=\frac{m_{p} \cdot x_{0}+m_{1} \cdot x_{1}}{m_{p}+m_{1}}$,

$y=\frac{m_{p} \cdot y_{0}+m_{1} \cdot y_{1}}{m_{p}+m_{1}}$,

$h=\frac{m_{p} \cdot h_{0}+m_{1} \cdot h_{1}}{m_{p}+m_{1}}$.

The vehicle's mass during the test was: $m_{P}=12285 \mathrm{~N} / 9.81 \mathrm{~m} / \mathrm{s}^{2}=1252 \mathrm{~kg}$.

\subsubsection{Only a driver inside the vehicle}

Assuming the coordinates describing the location of a driver inside a vehicle, it will be: $x_{K}=1.42 \mathrm{~m}, y_{K}=0.36 \mathrm{~m}, h_{K}=0.59 \mathrm{~m}$, placing a driver with mass:

$m_{K}=85 \mathrm{~kg}$ 


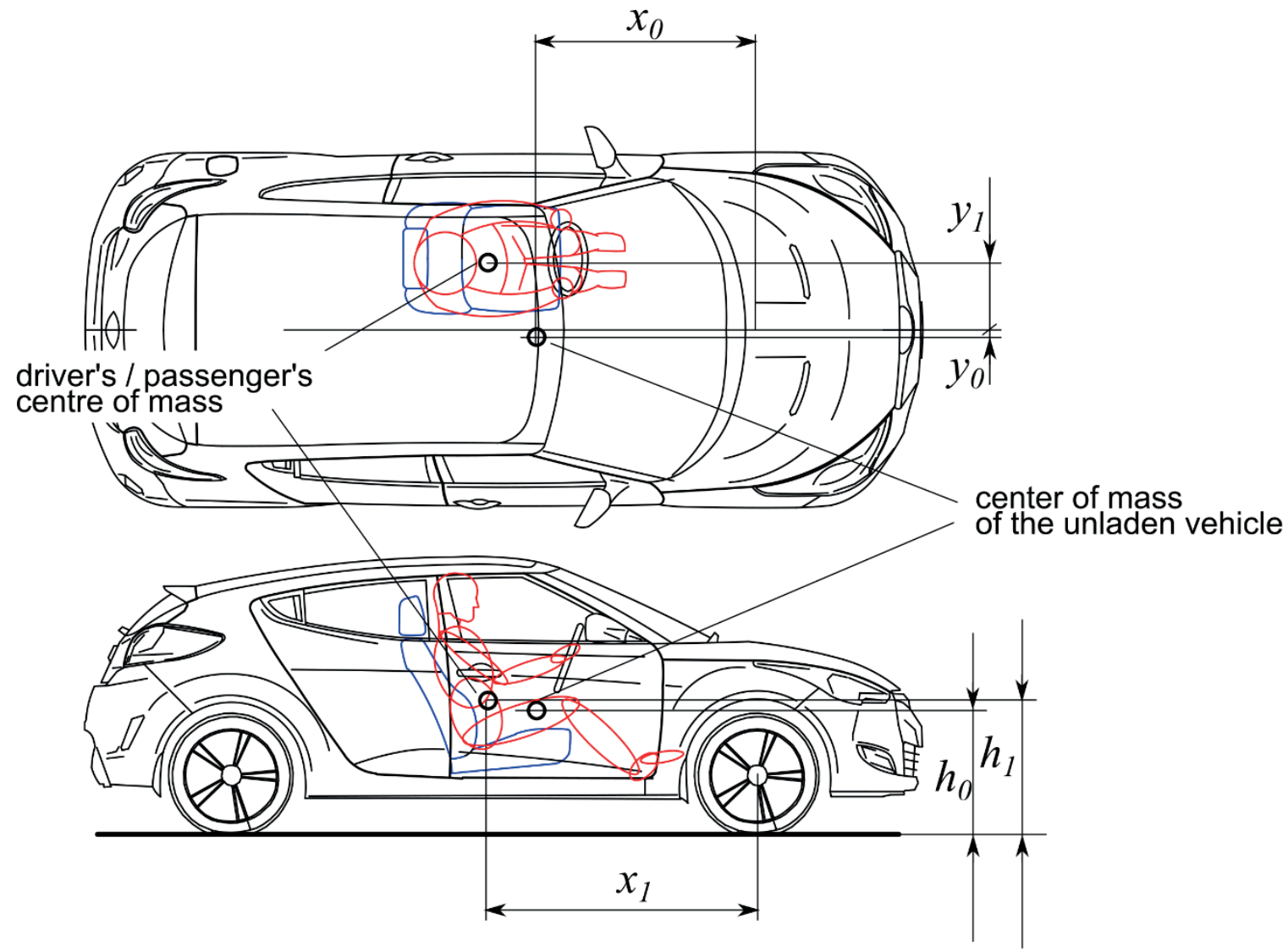

Figure 5 Position of the driver inside the passenger's compartment

results in displacement of the centre mass of the vehicle to new coordinates:

$$
\begin{aligned}
& x=\frac{1252 \mathrm{~kg} \cdot 0.412 \cdot 2.650 \mathrm{~m}+85 \mathrm{~kg} \cdot 1.42 \mathrm{~m}}{1252 \mathrm{~kg}+85 \mathrm{~kg}}=1.11 \mathrm{~m}, \\
& y=\frac{1252 \mathrm{~kg} \cdot 0.02 \mathrm{~m}+85 \mathrm{~kg} \cdot 0.36 \mathrm{~m}}{1252 \mathrm{~kg}+85 \mathrm{~kg}}=0.040 \mathrm{~m}, \\
& h=\frac{1252 \mathrm{~kg} \cdot 0.02 \mathrm{~m} \cdot 2.650 \mathrm{~m}+85 \mathrm{~kg} \cdot 059 \mathrm{~m}}{1252 \mathrm{~kg}+85 \mathrm{~kg}}=0.60 \mathrm{~m},
\end{aligned}
$$

where:

$y[\mathrm{~m}]$ - position relative to the longitudinal axis of the vehicle (positive direction - left),

$x[\mathrm{~m}]$ - position relative to the front axle of the vehicle (positive direction - backwards),

$h[\mathrm{~m}]$ - location relative to the road surface.

Placing the driver inside the vehicle does not significantly change the location of the centre of mass. $L_{1}=\frac{1.11 m}{2.650 m}=0.419$.

\subsubsection{Driver and passenger on the front seats}

$$
x=\frac{1252 \mathrm{~kg} \cdot 0.412 \cdot 2.650 \mathrm{~m}+85 \mathrm{~kg} .}{1252 \mathrm{~kg}+85 \mathrm{~m} \cdot 85 \mathrm{~kg} \cdot 1.42 \mathrm{~m}}
$$

$$
\begin{aligned}
y= & \frac{1252 \mathrm{~kg} \cdot 0.02 \mathrm{~m}}{1252 \mathrm{~kg}+85 \mathrm{~kg}+85 \mathrm{~kg}}=0.018 \mathrm{~m}, \\
& 1252 \mathrm{~kg} \cdot 0.226 \cdot 2.650 \mathrm{~m}+ \\
h= & \frac{+85 \mathrm{~kg} \cdot 0.59 \mathrm{~m}+85 \mathrm{~kg} \cdot 0.59 \mathrm{~m}}{1252 \mathrm{~kg}+85 \mathrm{~kg}+85 \mathrm{~kg}}=0.60 \mathrm{~m}, \\
L_{1}= & \frac{1.13 \mathrm{~m}}{2.650 \mathrm{~m}}=0.426 .
\end{aligned}
$$

2.5.3 Driver and passenger on the front seats, two passengers on the rear seats

$$
\begin{aligned}
& x=\frac{1252 \mathrm{~kg} \cdot 0.412 \cdot 2.650 \mathrm{~m}+170 \mathrm{~kg} \cdot}{1252 \mathrm{~kg}+85 \mathrm{~kg}+85 \mathrm{~kg}+85 \mathrm{~kg}+85 \mathrm{~kg}}=1.23 \mathrm{~m}, \\
& y=\frac{1252 \mathrm{~kg} \cdot 0.02 \mathrm{~m}}{1252 \mathrm{~kg}+85 \mathrm{~kg}+85 \mathrm{~kg}+85 \mathrm{~kg}+85 \mathrm{~kg}}=0.016 \mathrm{~m}, \\
& h=\frac{1252 \mathrm{~kg} \cdot 0.226 \cdot 2.650 \mathrm{~m}+}{1252 \mathrm{~kg}+85 \mathrm{~kg}+85 \mathrm{~kg}+85 \mathrm{~kg}+85 \mathrm{~kg}}=0.60 \mathrm{~m}, \\
& L_{1}=\frac{1.23 \mathrm{~m}}{2.650 \mathrm{~m}}=0.464
\end{aligned}
$$

Concluding obtained results, it is worth noting that even in the case of a relatively light passenger car, which 
was tested, with the weight of the driver and passengers loaded, in all the cases considered, the centre of mass of the loaded vehicle did not move significantly:

- in the longitudinal direction -0.02 to $0.04 \mathrm{~m}$,

- in the transverse direction - no more than $0.04 \mathrm{~m}$,

- vertically - up to about $0.02 \mathrm{~m}$.

\section{Conclusion}

Information about distribution of normal reaction forces between the left and right wheels may be important in the case of vehicle's motion modelling - development of active safety systems, accidents' reconstruction. Between the road surface and a tyre normal reaction forces arise. However, the tangential transverse and longitudinal forces arise as well, which are transmitted between the tyre and pavement, are dependent on these normal forces. So, to properly describe a vehicle's motion in roll, pitch or yaw direction, the authors showed the method of a vehicle's research, which allows for obtaining properties related to the stiffness of the front and rear axle. Mentioned properties of suspension are dimensionless. Thus, it is possible to compare the automobiles, which differ in dimensions. Similarly, the dimensionless parameters were applied for description of asymmetrical load of a vehicle, as well. Of course, presented method can be applied by automotive experts even if the normal forces between the wheels and road are unknown. In this case, they should be estimated after an assumption of a mass distributed between the front and rear axles and additionally between the left-hand and the right-hand sides of a car. Another assumption may refer to location of passengers inside the passengers' compartment, which was also exemplarily presented in this paper.

Conducted experiments were performed only for one vehicle and to confirm the results, it should be repeated for many automobiles.

\section{References}

[1] LOZIA, Z. Rollover thresholds of the biaxial truck during motion on an even road. Vehicle System Dynamics [online]. 1998, 29(sup1), p. 735-740 [accessed 2020-01-26]. ISSN 0042-3114, eISSN 1744-5159. Available from: https://doi.org/10.1080/00423119808969601

[2] POKORSKI, J., SAR, H., RENSKI, A. Influence of exploitation conditions on anti-skid properties of tyres. Transport [online]. 2019, 34(4), p. 415-424 [accessed 2020-01-26]. ISSN 1648-4142, eISSN 1648-3480. Available from: https://doi.org/10.3846/transport.2019.10426

[3] JURECKI, R. S., STANCZYK, T. L., JASKIEWICZ, M. J.. Driver's reaction time in a simulated, complex road incident. Transport [online]. 2017, 32(1), p. 44-54 [accessed 2020-01-26]. ISSN 1648-4142, eISSN 1648-3480. Available from: https://doi.org/10.3846/16484142.2014.913535

[4] LI, H., ZHAO, Y., LIN, F. ZHU, M. Nonlinear dynamics modelling and rollover control of an off-road vehicle with mechanical elastic wheel. Journal of the Brazilian Society of Mechanical Sciences and Engineering [online]. 2018, 40(2), p. 1-17 [accessed 2020-01-26]. ISSN 1678-5878, eISSN 1806-3691. Available from: https://doi.org/10.1007/ s40430-018-1009-8

[5] MASHADI, B. MOSTAGHIMI, H. Vehicle lift-off modelling and a new rollover detection criterion. Vehicle System Dynamics [online]. 2017, 55(5), p. 704-724 [accessed 2020-01-26]. ISSN 0042-3114, eISSN: 1744-5159. Available from: https://doi.org/10.1080/00423114.2016.1278076

[6] SELlAMI, Y., IMINE, H., BOUBEZOUL, A. CADIOU, J.-C. Rollover risk prediction of heavy vehicles by reliability index and empirical modelling. Vehicle System Dynamics [online]. 2018, 56(3), p. 385-405 [accessed 2020-01-26]. ISSN 0042-3114, eISSN 1744-5159. Available from: https://doi.org/10.1080/00423114.2017.1381980

[7] GHAZALI, M., DURALI, M. SALARIEH, H. Path-following in model predictive rollover prevention using front steering and braking. Vehicle System Dynamics [online]. 2017, 55(1), p. 121-148 [accessed 2020-01-26]. ISSN 0042-3114, eISSN 1744-5159. Available from: https://doi.org/10.1080/00423114.2016.1246741

[8] MA, Z., ZHANG, Y., YANG, J. Velocity and normal tyre force estimation for heavy trucks based on vehicle dynamic simulation considering the road slope angle. Vehicle System Dynamics [online]. 2016, 54(2), p. 137-167 [accessed 2020-01-26]. ISSN 0042-3114, eISSN 1744-5159. Available from: https://doi.org/10.1080/00423114.2015. 1122817

[9] DOUMIATI, M., VICTORINO, A., CHARARA, A., LECHNER, D. Lateral load transfer and normal forces estimation for vehicle safety: experimental test. Vehicle System Dynamics [online]. 2009, 47(12), p. 1511-1533 [accessed 2020-01-26]. ISSN 0042-3114, eISSN 1744-5159. Available from: https://doi.org/10.1080/00423110802673091

[10] ARCZYNSKI, S. Mechanics of automobile's motion / Mechanika ruchu samochodu (in Polish). Warszawa: Wydawnictwa Naukowo-Techniczne, 1993. ISBN 8320414881. 